\title{
Consumer Attitudes and Behaviors Regarding Ethnic Produce at Farmers’ Markets
}

\author{
Keiko Goto, Jennifer Whitten, Maria Giovanni, and Cindy Wolff \\ California State University, Chico
}

\begin{abstract}
Background and Objective: Past research indicates that exposure to ethnic produce may be positively associated with fruit and vegetable consumption and negatively associated with fast food consumption. The objective of this research was to examine attitudes and behaviors regarding ethnic produce among farmers' market consumers in rural northern California. Methods: A total of 502 farmers' market attendees completed a survey, which examined the demographic characteristics of the consumers, their attitudes toward ethnic produce at farmers' markets, and their familiarity and preferences for a variety of food products and cuisines. Results: Most participants had positive attitudes toward products presented on the survey. However, less than half of the study participants recognized at least 11 of the 22 ethnic produce items available at area farmers' markets. Ethnic minorities, females, and older participants were more likely to have tried ethnic produce items. Women had more positive attitudes toward ethnic produce. Conclusion: These findings indicate the importance of identifying strategies tailored to specific groups of people to promote the consumption of ethnic fruits and vegetables, which may be associated with lower rates of obesity and diet-related chronic diseases.
\end{abstract}

(C) 2014 Californian Journal of Health Promotion. All rights reserved.

Keywords: ethnic produce, food culture, farmers' markets, consumer survey, Hmong, Mexican.

\section{Introduction}

While obesity and diet-related chronic diseases have been identified as major public health concerns in the United States, research has shown the importance of understanding community and cultural assets that may positively affect healthy eating patterns (Flora and Gillespie, 2009). The knowledge of cultural food practices that refugees and immigrants bring to their new communities is a powerful tool for introducing healthful dietary practices to those in the host country. A recent study demonstrated a significant association between vegetable consumption and an open attitude toward food from other ethnic groups (Zhao, Goto, Wolff, Song, and Bianco-Simeral, 2013). Another study by Chen et al. (2014) showed that produce exposure was positively correlated with overall fruit and vegetable consumption and negatively correlated with fast food consumption among young children. These study results suggest that ethnic produce may become a vehicle for promoting fruit and vegetable consumption in the community.
Specifically, locally grown ethnic produce may foster the consumption of a variety of fruits and vegetables in a sustainable manner. Farmers' markets are a potential venue for promoting locally grown ethnic produce to different community members. These markets can expose primarily white consumers to various products including unfamiliar produce and foster social interaction and community building which promotes social cohesion in a community (Payet, Gilles, \& Howat, 2005; Hunt, 2006). Farmers' markets can also increase access to high quality foods and increase the variety of fruits and vegetables available, particularly in neighborhoods that have limited access to these foods (Larsen \& Gilliand, 2010; Markowitz, 2010). Further, promoting ethnic produce at farmers' markets may also provide financial benefit to ethnic minority vendors.

\section{Ethnic produce in Northern California}

California has the highest percentage of Latinos in the United States and this group accounts for $14 \%$ of the population in the study area. The 
Hmong are an Asian refugee group with an increasing population in the US. A significant proportion of the US Hmong population (35\%) resides in California (US Census, 2010). A total of 4,354 Hmong residents out of 91,224 Hmong in California resided in the study area in 2010 (US Census, 2010).

Not only are the Hmong and Mexican populations well represented in northern California, these two ethnic groups account for a sizable number of vendors at the local farmers' markets. A study of ethnic fruit and vegetable markets in Maryland revealed potential for increasing the production, marketing, and nutritional awareness of ethnic vegetables among consumers (Tubene, White, \& Rose, 2006). Likewise, recent studies indicate the need for farmers to participate in a niche market for ethnic vegetables as population demographics in various communities are changing (Adekunle, Filson, Sethuratnam, \& Cidro, 2011; Adekunle, Filson, \& Sethuratnam, 2012). An increased demand for ethnic vegetables may also encourage farmers from the dominant culture to grow ethnic vegetables (Adekunle et al 2012) and positively influence acceptance of ethnic food by the mainstream culture.

Limited information is available about the possible role of ethnic produce at farmers' markets in promoting the consumption of ethnic food products, which can contribute to overall fruit and vegetable consumption, as well as an increased variety of fruits and vegetables available for consumption. The objective of the current study was to assess consumer attitudes and behaviors regarding ethnic produce at area farmers' markets, with the aim of informing future strategies to promote

ethnic produce at farmers' markets and other locations. Past research suggests that demographic factors such as age and race/ethnicity may be associated with ethnic food attitudes and behavior (Verbeke and López, 2005). Therefore, the current study also examined associations between demographic variables and consumer attitudes and behaviors regarding ethnic produce at farmers' market.

\section{Methods}

\section{Study Design}

This study employed a quantitative consumer survey. The independent variables for the quantitative research component were demographic characteristics of survey participants such as race/ethnicity, age, and gender, as previous research indicates that demographic factors such as age and race/ethnicity are associated with ethnic food attitudes and behavior (Verbeke \& López, 2005). The dependent variables were attitudes toward farmers' markets and ethnic produce, consumer preferences for ethnic cuisines, and exposure to ethnic produce. The study was approved by the Human Subjects Committee at California State University.

\section{Participants and Procedures}

Survey participants who were 18 years or older were recruited at five farmers' market locations in the study area on five different days and times during a one week period. A script was used to ensure that data were collected consistently and no participants took the survey twice. The participants were recruited with a verbal invitation to voluntarily complete the survey and were not compensated. This convenience sampling resulted in 502 completed surveys. Participants were encouraged to complete the survey unaided, which took about five minutes. The survey was only provided in English. However, a research assistant was available to answer questions and administer the survey orally if requested by a participant. Anonymity was assured by using an identifying code for each farmers' market where the survey was implemented.

\section{Survey Instrument}

Prior to survey development, focus groups were first conducted with Hmong, Mexican and nonHispanic white participants to assess perceptions of ethnic produce at farmers' markets. The survey was developed based on responses from the focus groups, which were grouped into four themes: the importance of consumer attitudes and behaviors, the influence of the acceptance of immigrants' food culture by mainstream 
residents, divergent knowledge and attitudes regarding ethnic produce and ethnic cuisines, and farmers markets as a venue for promoting ethnic produce.

Survey questions were constructed by the researchers based on the results of the focus groups as well as by the literature. The survey assessed consumers' attitudes toward ethnic produce at farmers' markets, and previous exposure to and experience with ethnic produce items available at area farmers' markets. The survey also aimed to assess factors that impact consumer attitudes and behaviors regarding ethnic produce and reasons for shopping at farmers' markets. Participants were asked to rate their experience with 22 different produce items seasonally available at area farmers' markets. Among the 22 produce items, Ancho chile, Poblano pepper, chayote, tomatillo, avocado, serrano peppers, jalapeño, tunas, nopales (prickly pear cactus pad) represented Mexican culture, while bitter melon, mustard greens, long green beans, lemon grass and napa cabbage were identified as representing Hmong culture. The numbers of the Mexican ethnic produce items that were recognized, tasted, or prepared were computed to create three scale variables. Likewise, three scale variables were created to assess how many of those five Hmong items were recognized, tasted, or prepared by study participants. Jicama and cilantro, which are commonly consumed in both Mexican and Hmong cultures, were not included in these culture specific variables.

The content validity of the survey was confirmed by four nutrition professionals. The survey was pilot tested with six farmers' market attendees for face validity. Questions regarding income and education were not included as the pilot test indicated that including the sensitive information without providing incentives might jeopardize survey participation. The reliability of the survey instrument was measured using test-retest reliability with a test group of 18 participants. The average correlation coefficient was $r=0.850$, ranging from 0.596 to 1.00 .

\section{Data Analysis}

Descriptive and inferential statistics were used to analyze the survey data. Demographic information about each participant was collected and gender, age, race/ethnicity were used as independent variables to assess relationships with survey variables. A dichotomous variable for race/ethnicity (non-Hispanic white and other races) was used for data analysis. Chi-square tests examined differences between demographic variables and dependent variables such as attitudes toward ethnic produce, consumer preferences for ethnic cuisines, and exposure to and use of ethnic produce. Data were analyzed using SPSS 21.0 (Chicago: SPSS Inc., Chicago, IL), with significance at $\mathrm{p} \leq 0.05$.

\section{Table 1}

Demographic Characteristics of Study Participants $(n=502)$

\begin{tabular}{llr}
\hline Characteristics & & \multicolumn{1}{c}{$\mathrm{n}(\%)$} \\
\hline Gender & Female & $282(56.2 \%)$ \\
& Male & $216(43.0 \%)$ \\
Race/ethnicity & Decline to State & $4(0.8 \%)$ \\
& White & $307(61.2 \%)$ \\
& Asian & $47(9.4 \%)$ \\
& American & \\
& Indian/Alaska & $10(2.0 \%)$ \\
& Native & \\
& Native & \\
& Hawaiian/Pacific & $11(2.2 \%)$ \\
& Islander & \\
& Latino/Latino & $51(10.2 \%)$ \\
& Non- & $1(0.2 \%)$ \\
& Latino/Latino & $8(1.6 \%)$ \\
& Other Race & $21(4.2 \%)$ \\
& Two or more & $17(3.4 \%)$ \\
& Races & \\
& Decline to State & \\
& & \\
& $\leq 25$ & $170(33.9 \%)$ \\
& 26-45 (years) & $173(34.5 \%)$ \\
& 46-65 & $95(18.9 \%)$ \\
& $>65$ & $18(3.6 \%)$ \\
& Decline to State & $46(9.2 \%)$ \\
\hline n02 & &
\end{tabular}




\section{Results}

\section{Characteristics of Participants}

Survey participants ( $\mathrm{N}=502)$ were $56.2 \%$ female and $61.2 \%$ non-Hispanic white, with an average age of $35.1 \pm 15.0$ years. Demographic characteristics for survey participants are summarized in Table 1 . Over one quarter (28.1\%) of the respondents reported attending a farmers' market at least once per week while, $63.7 \%$ reported attending at least twice per month. Hence, more than $80 \%$ of survey respondents were frequent farmers' market participants.

Table 2

Participants' Attitudes Toward Ethnic Produce

\begin{tabular}{lccccc}
\hline & $\begin{array}{c}\text { Strongly } \\
\text { Agree } \\
\mathrm{n} *(\%)\end{array}$ & $\begin{array}{c}\text { Agree } \\
\mathrm{n}(\%)\end{array}$ & $\begin{array}{c}\text { Neutral } \\
\mathrm{n}(\%)\end{array}$ & $\begin{array}{c}\text { Disagree } \\
\mathrm{n}(\%)\end{array}$ & $\begin{array}{c}\text { Strongly } \\
\text { Disagree } \\
\mathrm{n}(\%)\end{array}$ \\
\hline $\begin{array}{l}\text { I am familiar with } \\
\text { most of the produce } \\
\text { sold at the farmers } \\
\text { market }\end{array}$ & $128(25.5 \%)$ & $222(44.2 \%)$ & $101(20.1 \%)$ & $38(7.6 \%)$ & $4(0.8 \%)$ \\
$\begin{array}{l}\text { I look for new or } \\
\text { unfamiliar produce at } \\
\text { the farmers' market }\end{array}$ & $98(19.5 \%)$ & $179(35.7 \%)$ & $144(28.7 \%)$ & $67(13.3 \%)$ & $5(1.0 \%)$ \\
$\begin{array}{l}\text { I would like to see } \\
\text { new ethnic produce at } \\
\text { the farmers' market }\end{array}$ & $124(24.7 \%)$ & $181(36.1 \%)$ & $160(31.9 \%)$ & $22(4.4 \%)$ & $1(0.2 \%)$ \\
$\begin{array}{l}\text { I like to support } \\
\text { farmers who sell } \\
\text { ethnic produce }\end{array}$ & $165(32.9 \%)$ & $176(35.1 \%)$ & $145(28.9 \%)$ & $4(0.8 \%)$ & $1(0.2 \%)$ \\
$\begin{array}{l}\text { I am willing to ask for } \\
\text { a sample of unfamiliar } \\
\text { produce }\end{array}$ & $151(30.1 \%)$ & $178(35.5 \%)$ & $116(23.1 \%)$ & $40(8.0 \%)$ & $6(1.2 \%)$ \\
$\begin{array}{l}\text { I am willing to ask the } \\
\text { farmer about their } \\
\text { produce }\end{array}$ & $167(33.3 \%)$ & $214(42.6 \%)$ & $97(19.3 \%)$ & $19(3.8 \%)$ & $0(0.0 \%)$ \\
\hline *n varies from 488 - 497 depending on survey item & & &
\end{tabular}

\section{Attitudes toward Ethnic Produce}

As shown in Table 2, many consumers reported that they would like to see new ethnic produce at the market (60.8\%), are willing to ask the farmer about the produce $(75.9 \%)$, and like to support farmers who sell ethnic produce (68.0\%). Gender was the most influential factor in determining the attitudes of farmers' market consumers towards ethnic produce. Women were significantly more likely to look for unfamiliar produce at the farmers' market $(p=.009)$ and would also like to see more ethnic produce at the farmers' market $(\mathrm{p}=.011)$. Race/ethnicity and age were not related to attitudes toward ethnic produce.

\section{Exposure to Ethnic Produce}

Respondents indicated their experience with different types of produce from a list of items (Table 3). Fewer than half of the study participants recognized at least 11 out of the 22 ethnic produce items. The produce items that were recognized by most respondents were those considered to be traditionally Mexican, such as jalapeños, avocados, and jícama. The most frequently mentioned produce items prepared by consumers were avocado, cilantro, and jalapeno pepper, all traditionally Mexican produce items that have become popular among non-Mexicans in California. Fewer than $30 \%$ of the study participants had prepared 11 or more of the 22 ethnic produce items. 
The most important factors related to exposure to ethnic produce were age and gender. Older and female respondents were significantly more likely to have recognized, tasted and prepared most of the 23 ethnic produce items compared to their counterparts. When Hmong and Mexican produce scale variables were used for analysis, the differences were all highly significant $(\mathrm{p}<$ 0.001); older and female respondents were significantly more likely to have recognized, tasted and prepared Hmong and Mexican produce items. Race/ethnicity was a significant factor associated with some of the less common types of produce items; respondents of other races were significantly more familiar with chayote $(p=.02)$ and bitter melon $(p=.003)$ compared to non-Hispanic white respondents. When the Hmong and Mexican produce scale variables were used, there was no significant difference in Hmong or Mexican produce exposures between non-Hispanic white respondents and those of other races.

\section{Table 3}

Survey Participants’ Exposure to Ethnic Produce Available at Area Farmers' Markets

\begin{tabular}{llrrr}
\hline Ethnic Produce & $\begin{array}{l}\text { Frequent user in } \\
\text { the study area }\end{array}$ & $\begin{array}{c}\text { Have Seen } \\
\mathrm{n} *(\%)\end{array}$ & $\begin{array}{c}\text { Have Tasted } \\
\mathrm{n}(\%)\end{array}$ & $\begin{array}{c}\text { Have Prepared } \\
\mathrm{n}(\%)\end{array}$ \\
\hline Ancho Chile & Mexican & $190(37.8 \%)$ & $181(36.1 \%)$ & $125(24.9 \%)$ \\
Poblano Pepper & Mexican & $212(42.2 \%)$ & $207(41.2 \%)$ & $150(29.9 \%)$ \\
Chayote & Mexican & $168(33.5 \%)$ & $139(27.7 \%)$ & $86(17.1 \%)$ \\
Jalapeño Pepper & Mexican & $419(83.5 \%)$ & $403(80.3 \%)$ & $351(69.9 \%)$ \\
Tomatillo & Mexican & $317(63.1 \%)$ & $302(60.2 \%)$ & $207(41.2 \%)$ \\
Serrano Pepper & Mexican & $222(44.2 \%)$ & $217(43.2 \%)$ & $156(31.1 \%)$ \\
Avocado & Mexican & $466(92.8 \%)$ & $464(92.4 \%)$ & $438(87.3 \%)$ \\
Jícama & Mexican/Hmong & $302(60.2 \%)$ & $286(57 \%)$ & $221(44 \%)$ \\
Bitter Melon & Hmong & $133(26.5 \%)$ & $91(18.1 \%)$ & $52(10.4 \%)$ \\
Mustard Greens & Hmong & $249(49.6 \%)$ & $209(41.6 \%)$ & $144(28.7 \%)$ \\
Long Green & Hmong & $386(76.9 \%)$ & $366(72.9 \%)$ & $310(61.8 \%)$ \\
Beans & Others & $293(58.4 \%)$ & $246(49 \%)$ & $193(38.2 \%)$ \\
Japanese Eggplant \\
Okra & Others & $316(62.9 \%)$ & $259(51.6 \%)$ & $170(33.9 \%)$ \\
Lemon Grass & Hmong & $280(55.8 \%)$ & $237(47.2 \%)$ & $146(29.1 \%)$ \\
Bok Choy & Others & $336(66.9 \%)$ & $300(59.8 \%)$ & $227(45.2 \%)$ \\
Daikon Radish & Others & $198(39.4 \%)$ & $163(32.5 \%)$ & $108(21.5 \%)$ \\
Napa Cabbage & Hmong & $258(51.4 \%)$ & $242(48.2 \%)$ & $176(35.1 \%)$ \\
Cilantro & Mexican/Hmong & $437(87.1 \%)$ & $440(87.6 \%)$ & $382(76.1 \%)$ \\
Fennel & Others & $220(43.8 \%)$ & $207(41.2 \%)$ & $129(25.7 \%)$ \\
Star Fruit & Others & $242(48.2 \%)$ & $182(36.3 \%)$ & $99(19.7 \%)$ \\
Tunas & Mexican & $191(38 \%)$ & $125(24.9 \%)$ & $63(12.5 \%)$ \\
Nopales & Mexican & $185(36.9 \%)$ & $132(26.3 \%)$ & $66(13.1 \%)$ \\
\hline \multirow{2}{*}{ N } & & &
\end{tabular}

* Number respondents answering "Yes"

\section{Discussion}

The current study examined attitudes and behaviors regarding ethnic produce among farmers' market consumers in rural northern California. Previous research indicates that the farmers' market setting encourages shoppers to 
try new produce (McCormack, Laska, Larson, \& Story, 2010). The results of the current study concur with these findings as farmers' market attendees in the study area are generally willing to try unfamiliar produce at the farmers' market when samples are available. Many consumers reported that they would like to see new produce at the market, are willing to ask the farmer about the produce, and like to support farmers who sell ethnic produce.

Our study results suggest that more knowledge of and exposure to ethnic produce from other cultures may be needed to increase consumer acceptance and use of this produce among farmers' market participants. Survey participants had limited knowledge of and exposure to different types of produce, especially Hmong produce items. Less than $30 \%$ of the study participants had prepared 11 or more out of the 22 ethnic produce items, suggesting that many consumers' exposure may be limited to popular restaurants. In a related qualitative study, farmers in upstate New York indicated that having cooking demonstrations with samples for tasting and recipes to prepare the food at home increased consumer interest and participation in the farmers' markets (Griffin \& Frongillo, 2003). Having food demonstrations and recipes to take home would encourage the use of ethnic produce.

Our study suggests that farmers' market consumers are not homogeneous. Age, gender and race/ethnicity appeared to be factors associated with consumer exposure to and attitudes toward ethnic produce items. Previous research suggests that these demographic factors are associated with ethnic food attitudes and behavior (Verbeke and López, 2005). While some participants may respond positively to ethnic food demonstrations, others may need different promotional strategies to convince them to try these produce items. Hunt (2006) suggests that interactions between consumers and vendors influence the quality and types of products sold at farmers' markets. Further research is needed to identify and evaluate effective ethnic produce promotion strategies tailored to different age, gender or ethnic groups. If ethnic produce items are too foreign to certain individuals such as young adults, strategies for incorporating those produce items into mainstream dishes (rather than promoting authentic dishes) through food demonstrations may increase their willingness to try those produce items.

Our farmers' market survey found that most respondents recognized traditionally Mexican produce items such as jalapeños, avocados, and jicama, indicating broad acceptance of this cuisine among the local community. Conversely, despite our survey participants' positive attitudes toward ethnic produce in general, survey participants' exposure to Hmong produce was limited. Our recent intervention study suggests that introducing ethnic produce to elementary school children and their parents increased children's preferences familiarity, and consumption of featured ethnic vegetables (Chen et al., 2014). Besides farmers' markets, multiple venues may be used to facilitate societal appreciation of ethnic food cultures.

\section{Limitations}

The limitations in this study are similar to other studies using a convenience sample. First, the survey data were self-reported, which may have created recall bias. Second, the convenience sample may have caused a selection bias and may not be representative of a wide range of consumers at farmers' markets. Additionally, we did not have a substantial number of Asian participants to make comparisons between Asians and non-Asians on our study variables. Finally, data regarding income and education, important demographic characteristics, were not obtained in the survey. Our past research (Ramsey, Wolff, Waite, Frigaard, BiancoSimeral, \& Goto, 2011) suggests that participants at the study area markets primarily consist of well educated, relatively high-income participants.

\section{Conclusion and Implications for Future Research}

The current study demonstrated generally positive attitudes toward ethnic produce among farmers' market consumers. This study also indicates that farmers' market consumers will need more knowledge and exposure to purchase 
and use ethnic produce. Other venues should be explored for promoting ethnic produce.

While the current study primarily focused on understanding attitudes and behaviors regarding ethnic produce among farmers' market consumers who are predominantly from the mainstream culture, information is limited regarding the link between ethnic produce promotion at farmers' markets and traditional dietary habits among ethnic minorities. Further research is needed to determine whether and how involving farmers' market consumers from the mainstream culture may contribute to societal acceptance of ethnic food cultures. Farmers' markets may have the potential to inspire socio-cultural change, including societal acceptance of ethnic food cultures. As suggested by Alkon and McCullen (2010), it is important to include farmers and vendors who can educate consumers by telling them culturally specific agrarian stories. Such conversations and discourse about food cultures can more easily happen in farmers market settings compared to other venues. More research is needed to examine whether and how farmers' market consumers who become more educated about ethnic produce may play roles in educating other consumers from the mainstream culture.

Finally, the current study suggests the importance of further understanding the impact of promoting locally grown ethnic produce at different venues such as farmers' markets on obesity prevention and health. Chen et al. (2014) found that ethnic produce exposure was positively correlated with overall fruit and vegetable consumption and negatively correlated with fast food consumption. Past research suggests that fruit and vegetable consumption is associated with a lower disease or obesity risk and better health (Van Duyn \& Pivonka, 2000; Ledoux, Hingle, \& Baranowski, 2010). Examining the relationship between ethnic produce exposure and BMI or other biomarkers related to chronic diseases will determine whether locally grown ethnic produce promotion may serve as an innovative way of preventing obesity and diet-related chronic diseases, which are major public health concerns in the United States.

\section{References}

Adekunle, B., G. Filson, \& Sethuratnam, S. (2012). Culturally appropriate vegetables and economic development. A contextual analysis. Appetite, 59(1),148-54. doi: 10.1016/j.appet.2012.04.003.

Adekunle, B., G. Filson, S. Sethuratnam, \& Cidro, D. (2011). Acculturation and consumption: Examining the consumption behavior of people of Afro-Caribbean descent in Canada. Journal of Agriculture, Food Systems, and Community Development, 2(1), 297-313. http://dx.doi.org/10.5304/jafscd.2011.021.001,

Alkon, A. H. \& McCullen, C. G. (2011). Whiteness and farmers markets: Performances, perpetuations ... contestations? Antipode, 43(4), 937-959. doi: 10.1111/j.1467-8330.2010.00818.x

Chen, Q., Goto, K., Wolff, C., Bianco-Simeral, S., Gruneisen, K., \& Gray, K. (2014). Cooking up diversity: impact of a multi-component, multi-cultural, experiential intervention on food and cooking behaviors among K-2 students from low-income ethnically diverse families. Appetite, 80,114-22.

Flora, C.\& Gillespie, A. (2009). Making healthy choices to reduce childhood obesity: Community capitals and food and fitness. Community Development, 40, 114-122.

Griffin, M. R., \& Frongillo, E. A. (2003). Experiences and perspectives of farmers from Upstate New York farmers' markets. Agriculture and Human Values, 20(2), 189-203.

Hunt, A.R. (2006). Consumer interactions and influences on farmers' market vendors. Renewable Agriculture and Food Systems, 22(1), 54-66. DOI: http://dx.doi.org/10.1017/S1742170507001597

Larsen, K. \& Gilliland, J. (2009). A farmers' market in a food desert: Evaluating impacts on the price and availability of healthy food. Health and Place, 15, 1158-1162. doi: 10.1016/j.healthplace.2009.06.007. 
Ledoux, T. A., Hingle, M. D., \& Baranowski, T. (2010). Relationship of fruit and vegetable intake with adiposity: A systematic review. Obesity Reviews, 12(5), e143-e150. doi: 10.1111/j.1467789X.2010.00786.X.

Markowitz, L. (2010). Expanding access and alternatives: Building farmers' markets in low-income communities. Food \& Foodways: History \& Culture of Human Nourishment, 18(1/2), 66-80. DOI:10.1080/07409711003708512

McCormack, L. A., Laska, M. N., Larson, N. I., \& Story, M. (2010). Review of the nutritional implications of farmers' markets and community gardens: A call for evaluation and research efforts. Journal American Dietetic Association, 110, 399-408.

Ramsey, E., Wolff, C., Waite, A., Frigaard, M., Bianco-Simeral, S., \& Goto. K. (2011). Challenges and opportunities in promoting locally grown food products among economically diverse consumers in rural northern California. California Dietetic Association Annual Meeting; Riverside, CA.

Tubene, S. L., White, O. B., \& Rose, M. (2006). Agricultural and demographic changes in the midAtlantic region: Implications for ethnic and specialty produce. Maryland Cooperative Extension. The Small Farm Institute.

U.S. Census Bureau (2010). US Census 2010. http://www.census.gov/2010census/ Website. Accessed 30 September, 2014.

Van Duyn, M.A., \& Pivonka, E. (2000). Overview of the health benefits of fruit and vegetable consumption for the dietetics professional: selected literature. Journal of the American Dietetic Association, 100(12), 1511-1521.

Verbeke, W. \& Lopez, G. P. (2005). Ethnic food attitudes and behaviour among Belgians and Latinos living in Belgium. British Food Journal, 107(11), 823-840.

Zhao, Y., Goto, K., Wolff, C., Song, C., Bianco-Simeral, S. (2013). Relationships between children's food consumption and social and cultural capital levels among Latino, Hmong,and Non-Hispanic White parents of K-2 children. Journal of Hunger and Environmental Nutrition, 8(4), 472-489.

Author Information

*Keiko Goto, PhD

Professor, Department of Nutrition and Food Sciences, Assistant Director, Center for Nutrition and Activity

Promotion , California State University, Chico

Address: CSU, Chico 0002, Chico, CA 95929-0002

Telephone Number: 530-898-6767

Fax: 530-898-5586

E-mail address: kgoto@csuchico.edu

Jennifer Whitten, MS, RD

Former Graduate Student, California State University, Chico

Maria Giovanni, $\mathrm{PhD}$

Assistant Professor, Department of Nutrition and Food

Sciences,

Address: CSU, Chico 0002, Chico, CA 95929-0002

Cindy Wolff, PhD, MPA, RD

Director, Center for Nutrition and Activity Promotion, California State University, Chico

Professor, Department of Nutrition and Food Sciences, California State University, Chico

* corresponding author 